\title{
FAMILIAL HEART DISEASE WITH SKELETAL MALFORMATIONS
}

\section{BY}

\author{
MARY HOLT AND SAMUEL ORAM \\ From the Cardiac Department, King's College Hospital \\ Received May 25, 1959
}

Owing to the increasing success of surgical treatment for congenital cardiac deformities, some patients who would otherwise have died will undoubtedly live to have children. The problem of the inheritance of cardiac anomalies has thus become of greater importance than before. It has always been a question, usually posed by the parents of the defective child, whether or not another sibling would be likely to be similarly affected. With modern surgery a further question arises, namely whether the frequency of the genes responsible may rise in the population.

The family reported here is thought to be of sufficient interest to warrant recording, since not only were subjects found with congenital cardiac defects throughout four generations, but these were closely linked with malformations in the skeletal system (Table I). The bony changes mainly

\section{TABLE I}

Family Tree showing Distribution of Associated Heart and Bone Lesions. There is no Consanguinity. The AFFECTED WOMAN FROM WHOM ALl ARE DESCENDED IS SAID TO HAVE HAD MANY RelativeS WITH HEART Disease. $\uparrow$ OR $\bar{c}=$ CONGENITAL HEART AND SKeletal Lesions

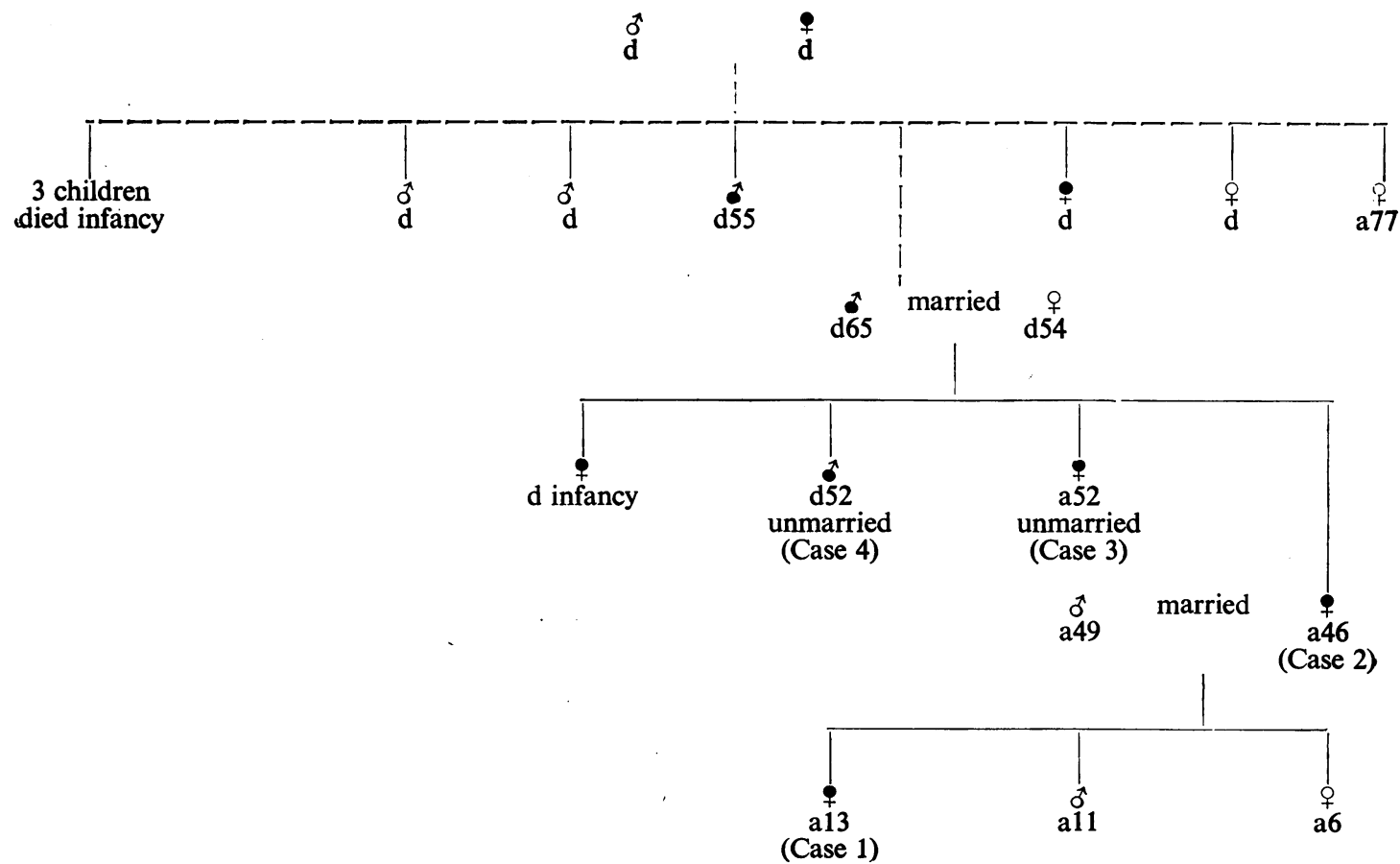

affected the upper limbs and were almost identical in several patients. The cardiac defects, too, appeared to be similar in character in each patient, atrial septal defect being confirmed at autopsy 
in one and being the probable diagnosis in the other three patients where clinical details could be obtained. In addition, all the patients showed a tendency to develop cardiac arrhythmias, often of bizarre type. In two of them cardiac catheterization was unsuccessful and a hypoplastic vascular condition seemed the probable cause.

There are many isolated reports of congenital heart disease affecting more than one member of a family, but it is only recently, with the analysis of large numbers of cases, that the relative frequency of this occurrence has been realized. Of 2000 families in which a case of congenital heart disease occurred, Campbell (1959) found additional affected members in 2 per cent. Wood (1958) found 5 per cent in a consecutive series of 1250 . Most commonly the further patients are found among the sibs of the presenting case, and McKeown et. al. (1953) concluded from a study of the 478 children with congenital heart disease born in Birmingham in the years 1940-49 that the incidence of such malformation is raised in sibs but not in parents and cousins of affected subjects. However, in the 40 families described by Campbell (1959) the additional cases lay outside the sib relationship in 16 instances.

On present evidence recurrence of the same type of congenital heart lesion within the family does not seem more likely to occur with one defect than another (Campbell, 1959). Gansslen et al. (1940), reviewing the subject of familial incidence, mentioned two instances where congenital heart disease was found in four generations, but such reports are rare, probably partly due to the difficulty of obtaining reliable information about those of the family not personally known to the living members. Hereditary factors in congenital heart disease are held to be, in the main, of recessive type (Cockayne, 1938; Polani and Campbell, 1955; and Campbell, 1959), but in most series the occasional family shows dominant inheritance, and the family that we report here is such an example.

\section{CASE RePORTS}

Case 1. A girl, now aged 13, was first seen at the age of 2, when she was thought to show undue fatigue. Normal activity has never caused dyspnœa, but she is subject to bronchitis, and had hæmoptysis on one occasion six years ago.

Clinical Features. Cardiovascular. Normal development and intelligence. No cyanosis or finger clubbing. Cardiac impulse of right ventricular type and felt in the anterior axillary line; pulmonary systolic murmur of grade 3 intensity accompanied by a faint thrill. Pulmonary second sound showing normal splitting and accentuated. Blood pressure 115/65. Radiologically there was moderately severe cardiac enlargement mainly of the right ventricle, with increased pulmonary vascular markings and slight hilar pulsation (Fig. 1A). The electrocardiogram showed a wandering pacemaker and nodal escape, alternating

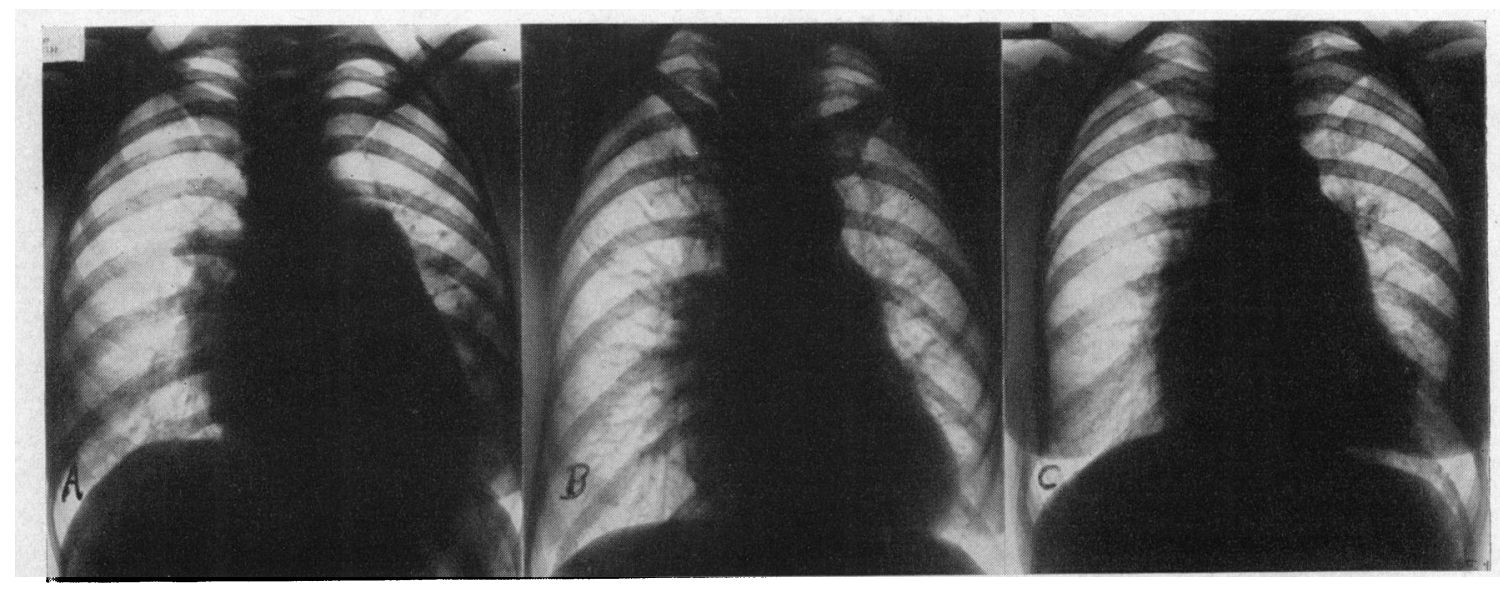

FIG. 1.-A, B, and C. Teleradiograms of Cases 1, 2, and 3 respectively, showing similarity in cardiac silhouette and lung fields. 
with periods of sinus rhythm with a P-R interval of $0.22 \mathrm{sec}$. There was right axis deviation but no evidence of hypertrophy (Fig. 2A). Cardiac catheterization was attempted but the catheter could not be introduced owing to extreme hypoplasia of the arm veins. Difficulty was experienced in puncturing the femoral artery, which also appeared to be hypoplastic.

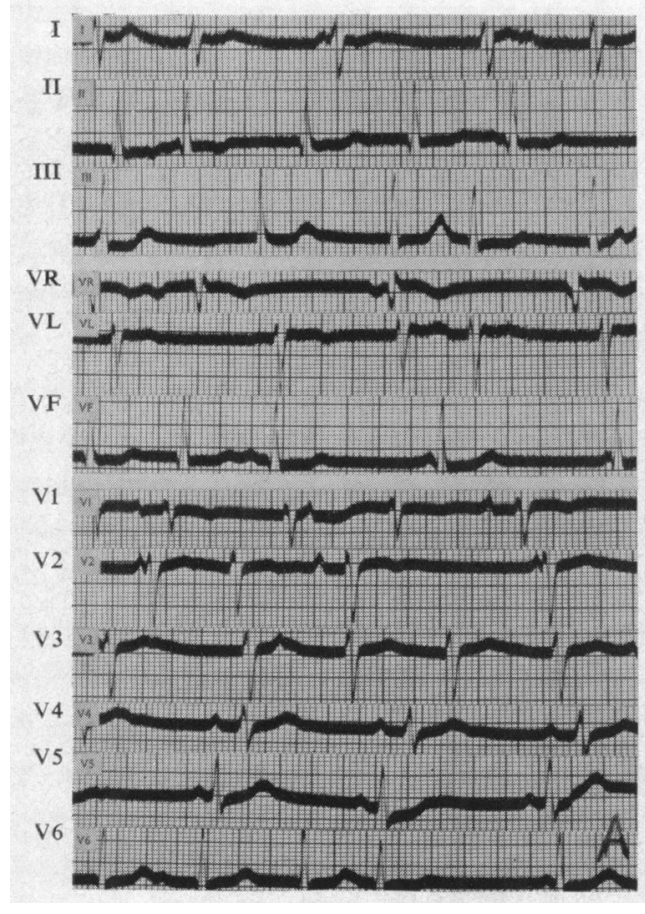

FIG. 2.-Electrocardiograms. (A) From Case 1 , showing right axis deviation, wandering pacemaker, and nodal escape, alternating with periods of sinus rhythm during which the $\mathbf{P}-\mathbf{R}$ interval reaches 0.22 sec. (lead V4).

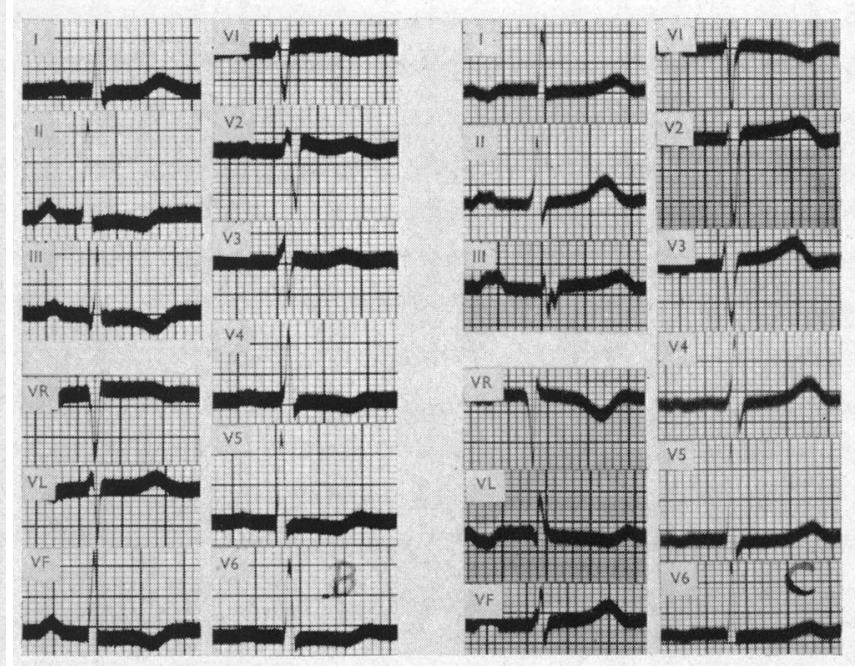

FIG. 2.-(B) From Case 2. Vertical heart. Sinus bradycardia and occasional interpolated vetricular ectopic beats and nodal escape. Bi-ventricular strain. (C) From Case 3, $\mathbf{P}-\mathbf{R}$ interval $\mathbf{0 . 2 8} \mathrm{sec}$. Bifid $\mathbf{P}$ waves inverted in leads I, V5, and V6. A prominent $U$ wave in most leads and sinus bradycardia.

Skeletal. There was a congenital anomaly of the thumbs which lay in the same plane as the fingers, their terminal phalanges being curved inwards (Fig. 3). The arch of the palate was high. Radiologically the scaphoid bone in both wrists was more longitudinal than normal. The carpal bones were generally slender. The left first and second metacarpal bones were elongated. The phalanges were rather short. The thumb on each side showed a rudimentary middle phalanx identical with that seen in the left hand of Case 2. This was a congenital dystrophy of bone.

Case 2. The mother of Case 1, aged 46, had been known to have heart disease since birth. She underwent uneventful pregnancies in 1945 and 1947, and the last in 1952 was complicated only by mild hypertension near term. She was free from symptoms until two years ago when slight effort dyspnœea was first noticed.

Clinical Features. Cardiovascular. Acyanotic. Right ventricular type of cardiac impulse felt just outside the mid-clavicular line. Blood pressure 145/80. A systolic murmur of grade 3 intensity best heard over the third left intercostal space close to the sternum, not accompanied by a thrill. Radiologically, enlargement of both ventricles and of the pulmonary outflow tract, with increased vascular markings in the lung fields (Fig. 1B). The electrocardiogram showed a vertical heart with biventricular strain, and sinus bradycardia with occasional interpolated ventricular ectopic beats and nodal escape (Fig. 2B). At cardiac catheterization conditions similar to those found in Case 1 prevented introduction of the catheter. Dye dilution curves were apparently normal.

Skeletal. Deformity of the hands, clinically almost identical with that of the daughter, was present (see Case 1). Radiologically the left hand and forearm showed that a congenital dystrophic condition had 
resulted in irregular growth of the ulna and the radius. The radio-carpal and radio-ulnar joints were irregular. The scaphoid had developed in two parts and the proximal of these showed an aseptic necrosis probably resulting from trauma and predisposed to by impaired nutrition. The lunate bone was deformed and its radial surface peaked. The phalanges were short and an accessory middle phalanx had developed in the thumb. There was hypoplasia of the first metacarpal. The right side shows minimal changes similar to those on the left (Fig. 4).
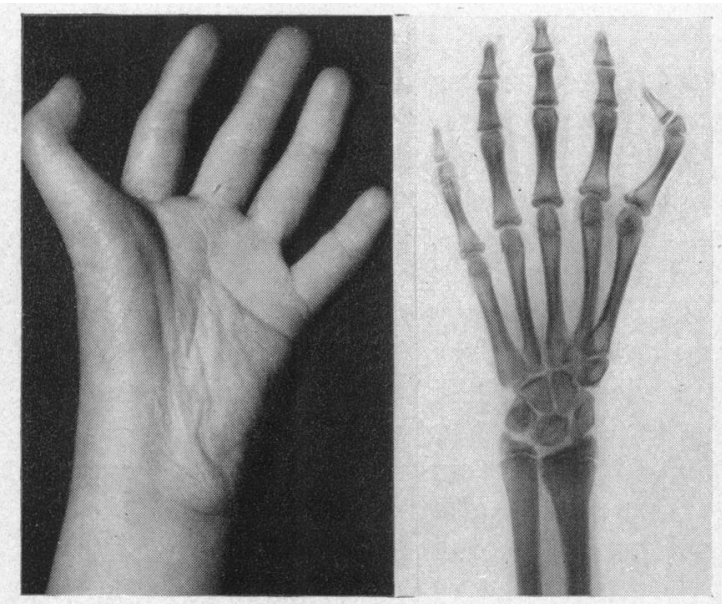

FIG. 3.-Left hand of Case 1, showing congenital anomaly of the thumb. The thumb lies in the same plane as the fingers, and the terminal phalanx points inwards.

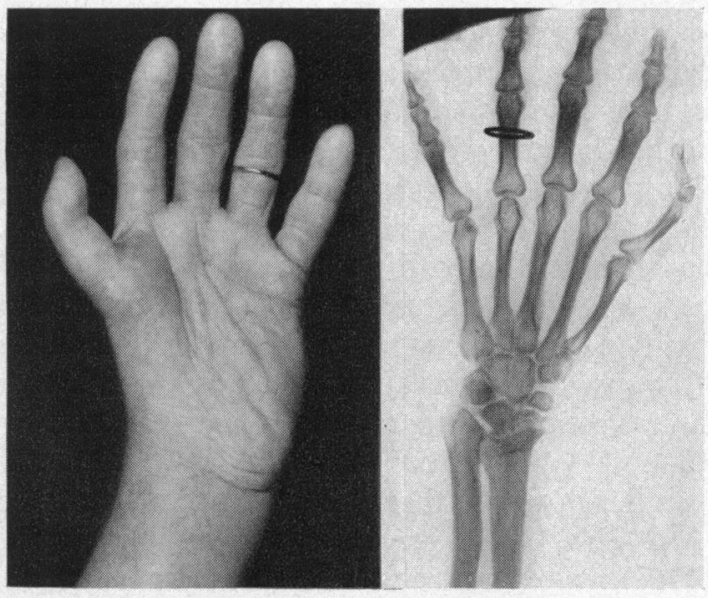

Fig. 4.-Left hand of Case 2, the mother of Case 1, showing similarity of the deformity of the thumb.

Case 3. The unmarried sister of Case 2, aged 52, was known to have had heart disease since birth, and had always been moderately dyspnœic on effort. In recent years she had developed recurrent bronchitis.

Clinical Features. Cardiovascular. Acyanotic. Cardiac impulse ill-defined. Blood pressure 140/85. Pulmonary systolic murmur of grade 3 intensity, accompanied by a thrill. Radiologically the cardiac silhouette suggested atrial septal defect (Fig. 1C). The electrocardiogram showed bradycardia with a P-R interval of $0.28 \mathrm{sec}$. and bifid $P$ waves inverted in the apical leads and standard lead $I$. A prominent $U$ wave was present in most leads (Fig. 2C). A subsequent record has shown auricular fibrillation.

Skeletal. There was dorsal kyphosis and sternal depression, with inability to elevate the arms above a right angle, suggesting Sprengel's deformity. The bone structure was radiologically normal apart from a minor anomaly of the medial end of the left clavicle.

Case 4. The unmarried brother of Cases 2 and 3, aged 52 was admitted to hospital with pulmonary œdema, having noticed increasing effort dyspnœea for six months. For the past three weeks he had been having attacks of paroxysmal nocturnal dyspnœa. He died suddenly two days after admission.

Clinical Features. Cardiovascular. Dyspnœic and slightly cyanosed. Cardiac rhythm irregular, apex rate 120 a minute. Apical impulse of right ventricular type felt in the mid-axillary line, with basal systolic ejection murmur and wide splitting of an accentuated pulmonary second sound. Congestive heart failure was present. Radiologically there was gross cardiac dilatation with bilateral pulmonary congestion. He had atrial fibrillation with multifocal ventricular ectopic beats together with right ventricular hypertrophy and right bundle-branch block.

Skeletal. The right hand showed malformation similar to that seen in Cases 1 and 2. In addition, the left forearm was shortened and curved, the hand having ulnar deviation and only four digits.

Autopsy. The heart weighed $850 \mathrm{~g}$., there being great dilatation and hypertrophy of both right atrium and ventricle. A smooth-walled circular defect, $3 \mathrm{~cm}$. in diameter, was present in the interatrial septum in the position of the foramen ovale. The lowest point of this orifice was situated $2.5 \mathrm{~cm}$. above the attachment of the aortic cusp of the mitral valve.

\section{Discussion}

Although the incidence of congenital heart disease in the sibs of affected patients is probably not greater than two per cent, it is higher than that calculated for the general population. Nevertheless, the frequency is not so high as to suggest that heredity plays the decisive part. The 
incidence in the parents of the propositi, namely the first children found to have heart disease in each of the families, is not higher than in the parents of the controls. In only one series (Lamy et al., 1957) was the amount of parental consanguinity significantly higher in the disease group than in the controls.

The weight of evidence seems to favour both genetic and environmental factors. It has been suggested that autosomal recessive genes are primarily responsible for the various lesions, but are of low penetrance so that they produce the lesions only under the influence of certain environmental factors or under the influence of genes at other loci (leader in Brit. med J., 1959, 1 704). However, our family showed inheritance of Mendelian dominant type.

Recurrence of the Same Cardiac Malformation. Writing of congenital malformations in general, Murphy (1936) concluded from a study of 884 families that if a malformed child possessed a malformed relative the defects were identical in 41 per cent of the cases. Similar studies in relation to congenital heart disease can be misleading if based on clinical data only, as the diagnosis often remains uncertain without special investigations. This may account for the wide divergence of opinion concerning the frequency with which the same cardiac malformation recurs. For example, Taussig (1947) gives an incidence as low as 2 per cent, while Wood (1958) writes that when congenital heart disease occurs in more than one member of a family it is nearly always of the same kind. Campbell (1959) found that the malformations were of the same or similar type in 26 out of 40 families in whom there was more than one patient with a congenital cardiac malformation.

With a view to providing more satisfactory material for studies of the hereditary factor, Davidsen (1958) makes a plea for the routine registration of the family history in cases of congenital heart disease, and the provision of detailed diagnostic data when familial cases are reported. It was with this need in mind that the patients under our care were submitted to cardiac catheterization, but unfortunately this proved technically impossible in the two on whom it was attempted, owing to vascular hypoplasia which appeared to be part of the clinical syndrome. Clinically and radiologically all four of our patients appeared to be suffering from the same lesion, and in one of them the presence of an atrial septal defect was confirmed at autopsy.

Associated Non-cardiac Malformations. In patients with congenital heart defects the incidence of associated malformations was estimated at 21 per cent by MacMahon et al. (1953). The discovery of the family reported here with its associated cardiac and skeletal malformations prompted us to search the case records of King's College Hospital for other examples of this association. Our findings are summarized in Table II. Ten of the fourteen patients had deformities affecting the upper limbs, but in only three was this the sole skeletal anomaly. In five there were also congenital lesions other than cardiovascular. This group did not yield any further examples of atrial septal defect, the cardiac lesion being patency of the ductus arteriosus in five, ventricular septal defect in four, and miscellaneous lesions in the remainder.

The numbers are, of course, too small to have any statistical significance but certainly our findings do not concur with those of Oppenheimer et al. (1949) who observed several cases of rare anomalies of the osseous system associated with a cardiac malformation which was invariably an atrial septal defect, with or without mitral stenosis. In his autopsy series of 200 cases Wiland (1956) found pure atrial septal defect to be the lesion most commonly accompanied by extracardiac defects, which were present in half the cases. However, there were no patients with atrial septal defect among the five examples of congenital heart disease associated with malformations of the hands reported by Calo (1953); in two the diagnosis was ventricular septal defect and in a third Fallot's tetralogy. This is of interest in view of Wood's (1958) observation, based on a consecutive series of 1250 cases of congenital heart disease, that in seven out of eight instances deformities of the limbs were associated with ventricular septal defect, and that the three cases with polydactyly each had Fallot's tetralogy. In face of these different findings it must be concluded that present evidence does not show any constant association between a specific extra-cardiac malformation and a particular type of cardiac malformation.

In the family that forms the basis of this report, the skeletal changes were largely confined to the 
TABLE II

Associated Cardiac and Skeletal Anomalies

\begin{tabular}{|c|c|c|c|}
\hline $\begin{array}{l}\text { Case } \\
\text { No. }\end{array}$ & $\begin{array}{l}\text { Sex } \\
\text { and } \\
\text { age }\end{array}$ & Heart lesion & Other malformations, all but four being skeletal \\
\hline 1 & M., 20 y. & Pulmonary stenosis* & Cervical scoliosis with torticollis, cleft palate \\
\hline 2 & M., $3 \mathrm{~d}$. & Eisenmenger syndrome $\dagger$ & Talipes equinovarum. Also horse-shoe kidney \\
\hline 3 & F 16 y. & Patent ductus arteriosus & Marfan's syndrome \\
\hline 4 & F 13 y. & Patent ductus arteriosus* & $\begin{array}{l}\text { Arachnodactyly, genu valgum, and thoracic scoliosis. } \\
\text { Also congenital strabismus }\end{array}$ \\
\hline 5 & F 8 y. & Patent ductus arteriosus* & $\begin{array}{l}\text { Partial syndactyly second and third toes each foot. } \\
\text { clinodactyly. Also epilepsy }\end{array}$ \\
\hline 6 & M., 9 у. & Patent ductus arteriosus* & $\begin{array}{l}\text { Webbing } 1 . \text { hand and hyperteleorism. Also agenesis } \\
\text { r. upper lobe of lung }\end{array}$ \\
\hline 7 & F., 4 y. & Patent ductus arteriosus* & Genu valgum, cleft palate \\
\hline 8 & F., 4 y. & Ventricular septal defect & $\begin{array}{l}\text { Supernumerary phalanx } 1 \text {. thumb, slight hyperteleor- } \\
\text { ism, upper dorsal spina bifida, D6 and } 7 \text {, hemi- } \\
\text { vertebræ }\end{array}$ \\
\hline 9 & F., 7 y. & Ventricular septal defect & Absent terminal phalanx 1 . fifth finger \\
\hline 10 & M., 14 y. & Ventricular septal defect & Absent terminal phalanx 1 . fifth finger \\
\hline 11 & M., 15 y. & Ventricular septal defect* & $\begin{array}{l}\text { Brachydactyly with absent middle phalanx } 1 \text {. fifth } \\
\text { finger, all finger-nails hypoplastic }\end{array}$ \\
\hline 12 & F., 2 d. & Persistent ostium primum $\dagger$ & $\begin{array}{l}\text { Absent } 1 \text {. radius and thumb, and cleft palate and hare } \\
\text { lip }\end{array}$ \\
\hline 13 & F., 11 y. & $\begin{array}{l}\text { Acyanotic CHD? with cardiac } \\
\text { myopathy }\end{array}$ & $\begin{array}{l}\text { Ulnar deviation of terminal phalanges index fingers, } \\
\text { genu valgum, and pes planus }\end{array}$ \\
\hline 14 & F., $12 \mathrm{~d}$. & Congenital heart disease & $\begin{array}{l}\text { Absent femurs, spinal defects, deficient mandible, and } \\
\text { cleft palate }\end{array}$ \\
\hline
\end{tabular}

* Confirmed at operation.

$\dagger$ Confirmed at necropsy.

hands, and osseous abnormalities affecting the hands occurred in 10 of the 14 patients with congenital heart disease mentioned in Table II, involvement of the feet being noticeably less common. That this is not a chance association is supported by the observation of Wiland (1956) that although anomalies of the musculo-skeletal system were extremely variable and usually multiple, malformations of the fingers were the most common.

The limb buds appear in the embryo in the fourth week of fœtal life, at the time when the primitive heart tube is beginning to differentiate, and the main development of both limbs and heart takes place simultaneously in the next two weeks (Arey, 1954). The upper pair of limb buds appears first and their growth is completed in advance of the lower; we suggest that this may account for the preferential involvement of the upper limbs in congenital defects.

\section{SUMMARY}

Details are given of a family in which members of four generations were affected by both congenital heart disease and skeletal anomalies. In both systems the malformation appeared to be 
of similar type in all the affected members, the former being an atrial septal defect, often accompanied by bizarre arrhythmia, and the latter affecting mainly the hands. There was also evidence of hypoplasia of the peripheral arteries and veins. The inheritance was of Mendelian dominant type.

Among reported cases there are few examples of familial congenital heart disease involving as many as four generations, and hereditary factors are usually considered to be of recessive type. Cardiac malformations affecting more than one member of a family tend to be similar in character. Evidence is conflicting regarding the association of particular non-cardiac malformations with any one form of heart lesion. Abnormalities of the hands, however, do seem to be particularly liable to appear in conjunction with cardiac malformations and the embryological factors that may be responsible are discussed.

In order to provide satisfactory material for further study of heredity and allied problems in congenital heart disease there is a need for the routine registration of a detailed family history in all cases, and full investigation of familial examples with a view to the establishment of an accurate diagnosis.

Although too little is yet known concerning the causation of congenital heart disease for any preventive measures, sufficient is known for the cardiologist to be able to reassure parents who have had one affected child that, provided there is no other family history of congenital heart defect and the parents are unrelated, the chances of a further child being affected are less than one in fifty.

We thank Dr. Ronald Hartley for kindly providing us with details of Case 4, Dr. A. M. Rackow for the radiological reports on the bony changes in Cases 1 and 2, and Dr. J. H. Renwick for help with the genetic aspect.

\section{REFERENCES}

Arey, L. B. (1954). Developmental Anatomy. 6th ed., W. B. Saunders Co., Philadelphia and London.

Calo, A. (1953). Cuore e Circolazione, 37, 303.

Campbell, M. (1959). Brit. Heart J., 21, 65.

Cockayne, E. A. (1938). Quart. J. Med., 7, 479.

Davidsen, H. G. (1958). Acta. med. Scand., $160,447$.

Gansslen, M., Lambrecht, K., and Werner, M. (1940). Just's Handbuch der Erbbiologie des Menschen. Vol. 4, p. 198, Springer, Berlin.

Lamy, M., de Grouchy, J., and Schweigguth, O. (1957). Amer. J. hum. Gen., 9, 17.

McKeown, T., MacMahon, B., and Parsons, C. G. (1953). Brit. Heart J., 15, 273.

MacMahon, B., McKeown, T., and Record, R. G. (1953). Brit. Heart J., 15, 121.

Murphy, D. P. (1936). Surg. Gyn. Obst., 63, 443.

Oppenheimer, B. S., Blackman, N. S., and Grishman, A. (1949). Trans. Ass. Amer. Phys., 62284.

Polani, P. E., and Campbell, M. (1955). Ann. hum. Genet., 19, 209.

Taussig, H. B. (1947). Congenital Malformations of the Heart. Oxford University Press.

Wiland, O. K. (1956). Lab. Invest., 5, 380.

Wood, P. (1958). Brit. med. J., 2, 701. 